\title{
A CONCRETIZAÇÃO DO DIREITO FUNDAMENTAL À SAÚDE PERSPECTIVADA NO CONSTITUCIONALISMO CONTEMPORÂNEO
}

\author{
THE REALIZATION OF THE FUNDAMENTAL RIGHT TO HEALTH VIEWED IN THE \\ CONSTITUTIONALISM CONTEMPORARY
}

Renato Gobetti de Souza*

Data de recebimento: $23 / 02 / 2015$

Data da aprovação: 10/06/2015

\section{RESUMO}

A Constituição Federal do Brasil de 1988, influenciada pelos ditames de um novo constitucionalismo, reconheceu a posição central e de destaque dos direitos fundamentais. De fato, a nossa Carta tem assegurada a eficácia jurídica de todo seu texto, notadamente das normas constitucionais definidoras de direitos fundamentais, deixando de ser um documento meramente político e ideológico para ser detentor de forte carga axiológica, normativa, vinculante e suprema. Inaugura-se no Brasil com a atual Constituição um novo modelo de Estado, marcadamente social e intervencionista, responsável por tarefas, programas e fins a serem executados por meio de prestações positivas oferecidas à sociedade. Exige-se, hodiernamente, uma atuação efetiva do Estado na materialização real dos direitos fundamentais, sobretudo sociais, com o propósito de servir a coletividade e prover os indivíduos de condições materiais mínimas de existência. Nesse cenário, não se admite mais a falta de efetividade do direito à saúde, um direito de textura fundamental, vinculado à preser-

\footnotetext{
* Mestrando em Teoria do Direito e do Estado pelo UNIVEM. Especialista em Direito do Estado, com formação para o Magistério Superior, pela Universidade Anhanguera-Uniderp. Graduado pela FMU. Professor nos cursos preparatórios para concurso público Opção Concursos - Marília/SP e Esquema Concursos - Marília/SP. Advogado.

E-mail: regobetti@gmail.com
} 
vação da vida e da dignidade da pessoa humana. Dessa forma, o contributo desse trabalho é apresentar subsídios teórico-dogmáticos e práticos necessários para plena concretização do direito à saúde, evidenciando a atual incúria do Poder Público no atendimento desse direito.

\title{
PALAVRAS-CHAVE
}

Constitucionalismo contemporâneo. Constituição Federal de 1988. Direitos fundamentais. Eficácia e aplicabilidade das normas de direitos fundamentais. Direito à saúde.

\begin{abstract}
The Constitution of 1988, influenced by the dictates of a new constitutionalism, recognized the centrality and prominence of fundamental rights. In fact, our Charter has ensured the legal force of all of your text, notably the constitutional rules that define fundamental rights, no longer merely a political and ideological document to be in possession of strong charge axiological normative, binding and supreme. With the current Constitution a new state model is inaugurated in Brazil. It is strongly social and interventionist responsible for tasks, purposes and programs to be implementend by means of positive benefits offered to society. It is required now, an effective state action in the real embodiment of fundamental rights, mainly social, with the purpose of serving the community and individuals to provide minimum substantive existence. In this scenario, it is no longer acceptable the lack of effectiveness in the right to health, a right of fundamental texture, linked to the preservation of life and human dignity. Therefore, this paper aimed to present theoretical-dogmatic and practical elements which are essential for full realization of the right to health, highlighting the current neglect of the government in meeting this right.
\end{abstract}

\section{KEYWORDS}

Contemporary constitutionalism. The Constitucion of 1988. Fundamental rights. Efficacy and applicability of fundamental rights. Right to health. 


\section{INTRODUÇÃO}

A concretização dos direitos fundamentais vem perspectivada na consciência ética coletiva, como fundamento filosófico último dos direitos fundamentais, que é um processo histórico. Seu aprofundamento e ampliação se dá com o evolver da História.

Contemplar a dignidade da condição humana exige o respeito a certos valores em qualquer condição, a justificar a imposição dos pretéritos direitos humanos, relativamente aos direitos liberais, e posteriormente de outras condições sociais aptas a propiciar a realização de todas as virtualidades do ser humano, materializadas pela formulação de novos direitos fundamentais. É, portanto, o processo histórico de expansão e afirmação progressiva dos direitos humanos fundamentais que justifica a adequada leitura do direito fundamental à sáude.

No século XX, a temática dos direitos humanos foi marcada por profundas contradições. De um lado, o Estado do Bem-Estar Social do pós segunda guerra mundial pareceu concretizar o ideal de uma sociedade identificada com a igualdade de condições básicas de vida para as pessoas e de outro lado o moviemto neoliberal que permeou o fim do século XX e início deste demonstrou um déficit do princípio da igualdade, base dos direitos sociais, com a resistência universal dos ideais individualistas.

Mas, sem olvidar que essas contradições são naturais do processo histórico de conquista de uma nova convivência em sociedade, vislumbra-se um mundo em transição, caminhando para uma resistência aos ideais políticos, econômicos e sociais do sistema neoliberal e para o fortalecimento de um Estado Social. A impossibilidade de cumprir as demandas sociais propõe uma mudança de rumo, com a diminuição da desigualdade entre os povos, a ascensão democrática com a inclusão da população no curso do desenvolvimento, a não contenção do trabalho vivo e a efetivação dos direitos fundamentais.

Como observa Bonavides (1985, p. 631):

Com o Capítulo da Ordem Econômica e Social, a definição nas Constituições em favor de um Estado social tem sido ostensiva. Até onde vai ou pode ir em sistemas democráticos essa opção do constituinte e como concretizá-la numa sociedade capitalista, eis o problema que desafia juristas, publicistas e homens de Estado. (...) A clara opção constitucional de alguns sistemas pluralistas por um Estado social tem levado a fazer da ordem econômica e social senão o mais importante capítulo da Constituição, 
pelo menos aquele onde se escreve a verdadeira essência e finalidade de um novo modelo de Estado que, adotando a fórmula de consenso, pretenda lograr a consecução de objetivos sem os quais, princípios da importância fundamental da igualdade ficariam consideravelmente deficitários ou desfalcados de seus componentes democráticos.

Amparada nessa transição, a Constituição brasileira de 1988 consagra em seu texto um Estado Social Democrático de Direito, sendo influenciada pelos ditames de um novo movimento social, político e jurídico denominado Constitucionalismo contemporâneo.

Em verdade, o Constitucionalismo contemporâneo é a representação da mais avançada experiência constitucional, dentro do desenvolvimento histórico do constitucionalismo ou dentro daquilo que Canotilho (1997, p. 51) denominou de movimentos constitucionais e para a exata compreensão de seu estágio e suas exigências convém um retorno na quadra da história.

Não obstante a existência e cooperação do Constitucionalismo antigo, identificado pelas experiências do Estado Hebreu, Grego e Romano, Tavares (2002) salienta que é na Idade Média que o consticionalismo ressurge como movimento de conquista das liberdades individuais, impondo barreiras à atuação soberana, assegurando os direitos individuais em combate à opressão estatal. Nesse período é que o constitucionalismo é marcado como uma nova teoria que apresenta um conjunto de ideias consubstanciadoras do princípio do governo limitado, representando uma técnica específica de limitação do poder com fins garantísticos, como define Canotilho (1997).

Percebe-se que, a partir deste momento, o constitucionalismo começa a ganhar força e com o desenvolvimento do liberalismo, no plano político, tem suas aspirações consolidadas. Emerge a idéia e a necessidade de Constituição.

Advém o constitucionalismo liberal clássico do final do século XVIII com as revoluções liberais burguesas. A Constituição norte-americana (1787), com a primeira Constituição escrita e rígida dotada de supremacia e a idéia da garantia jurisdicional, mais a Constituição francesa (1791), alicerçada na garantia dos direitos e na separação dos poderes, bem representam esse período.

A partir desse momento a noção de Constituição, conforme ressalta Cunha Júnior (2008), envolve uma força capaz de limitar e vincular todos os órgãos do poder político. Manifesta-se como uma norma suprema e fundamental, pois é hierarquicamente superior a todas as outras, ficando instituído um sistema de responsabilização jurídico-política do poder que a desrespeitar.

Contudo, é com o fim da primeira guerra mundial e na impossibilidade 
de cumprir as demandas sociais exigidas no século XIX que o Constitucionalismo moderno começa a propor uma mudança de rumo.

Cunha Júnior (2008) observa que as Constituições passaram a configurar um novo modelo de Estado, antes liberal e passivo, agora social e intervencionista, responsável pelo cumprimento de tarefas e programas perante à sociedade. Com o Estado Social há uma metamorfose da Constituição, de Garantia, Defensiva ou Liberal para Dirigente, Programática ou Constitutiva.

Começa a florescer o Constitucionalismo contemporâneo que vai se fortalecer e apresentar suas exigências bem marcadas após o fim da Segunda Guerra Mundial, alicerçando-se nos pilares da dignidade da pessoa humana como valor constitucional supremo, da rematerialização constitucional com a previsão de um rol de direitos fundamentais e de opções, diretrizes e valores a serem seguidos pelos poderes públicos e do reconhecimento da força normativa das constituições.

Moreira (2008) registra que a rematerialização e o caráter jurídico das constituições no novo constitucionalismo provocam transformações na estrutura das ciências jurídicas, pois apresentam uma releitura da teoria da norma, das fontes e da interpretação.

$\mathrm{Na}$ teoria da norma as grandes mudanças são o reconhecimento da normatividade dos princípios, ou seja, os princípios são erigidos à categoria de normas e as normas programáticas não são meros conselhos, são vinculantes e obrigatórias.

Na teoria das fontes a principal alteração se dá no papel do Poder Judiciário, sendo mais ativo, sobretudo, nas relações políticas e sociais, diferentemente do positivismo em que o Legislativo desempenhava um papel de destaque. É nesse cenário que emerge o controle judicial de políticas públicas.

Por fim, na teoria da interpretação o avanço é verificado nos novos métodos específicos de interpretação constitucional, sendo que no Constitucionalismo contemporâneo toda interpretação jurídica deve passar obrigatoriamente por uma análise constitucional.

Barroso (2005), com domínio ímpar do assunto, resume os avanços propiciados pelo novo constitucionalismo. O primeiro marco, o histórico, é a formação do Estado constitucional de direito; o segundo marco, o filosófico, é a centralidade dos direitos fundamentais e a reaproximação entre Direito e ética; por fim, o marco teórico inclui a força normativa da Constituição, a expansão da jurisdição constitucional e o desenvolvimento de uma nova dogmática da interpretação constitucional.

Nessa nova realidade, Lenza (2009) observa que não se pode mais atrelar o constitucionalismo à idéia de limitação do poder, mas sim à busca da eficácia da 
Constituição, abandonando o texto a característica da retórica e passando a ser mais efetivo, principalmente na concretização dos direitos fundamentais.

É nesse ambiente que se convoca o aprofundamento e o aprimoraramento do estudo da teoria dos direitos fundamentais e da defesa da plena efetividade e concretude desses direitos.

A concretização dos direitos fundamentais, sobretudo dos direitos sociais, impõe a superação das resistências inerentes à concepção liberal de Estado e da ciência jurídica dotada de subsídios teórico-dogmáticos tradicionais. Assim, na perspectiva de uma nova teoria do direito, da aproximação da filosofia e do constitucionalismo contemporâneo novos horizontes se abrem para os direitos fundamentais. A superação histórica do jusnaturalismo e o fracasso político do positivismo abrem caminho para um conjunto amplo de reflexões acerca do Direito, sua função social e sua interpretação. O positivismo, enquanto teoria jurídica, deixa de constituir a alternativa viável para orientar a interpretação e aplicação do direito, tendo em vista que não leva em consideração o aspecto ideal do Direito, as ideias de correção, justiça, razoabilidade e a aproximação entre Direito e Moral. Exsurge, portanto, o pós-positivismo, alinhado ao desenvolvimento do Direito em sociedades relativamente complexas, como uma concepção teórica, na qual se incluem a definição das relações entre valores, princípios e regras, aspectos da chamada nova hermenêutica constitucional e a teoria dos direitos fundamentais, edificada sobre o fundamento da dignidade humana.

\section{OS DIREITOS FUNDAMENTAIS SOCIAIS}

Miranda (1996) ensina que a compreensão histórica dos direitos fundamentais exerce um papel extraordinariamente importante, pois permite verificar a variedade de condições de realização dos direitos do homem, dentro da unidade do gênero humano, as experiências em confronto, ora de sedimentação, ora de crise e a descoberta de novos percursos e novos avanços.

Assim, os direitos convencionados como de primeira dimensão, direitos civis e políticos, direitos fundamentais relacionados à liberdade, se desenvolveram em determinado momento histórico e desempenharam sua função na fundação da civilização moderna.

Contudo, com o avanço civilizacional ficaram claras suas insuficiências e o papel do Estado de somente garantir os direitos de liberdade sem interferências, noção de Estado mínimo, começa a perder seu poder de convicção social, afetando o 
exercício estável do poder estatal. Fica enfraquecido o reconhecimento de legitimidade da ordem social, conforme aclara Comparato (2000-2001).

Agigantam-se as desigualdades socioeconômicas no século XX. Segundo Cunha Júnior (2008) os desequilíbrios contínuos gerados pela livre concorrência, eis que não existia o equilíbrio automático da oferta e da procura, a inexistência da garantia da justa renda, do justo preço, do justo lucro, do justo salário, em razão da concentração de capitais, e o aproveitamento das facilidades geradas pelo regime da iniciativa privada fizeram com que os fracos fossem oprimidos pelos fortes.

Nesse cenário, o Estado evolui para intervir nos setores econômicos e sociais da sociedade, passando a ser mais participativo e decisivo na implementação de direitos. O Estado passa a ser prestador de serviços.

Surgem, assim, os direitos sociais, econômicos e culturais, denominados direitos fundamentais de segunda dimensão, intrinsecamente relacionados à idéia de igualdade material.

Com efeito, no Estado do Bem-Estar Social os direitos sociais e econômicos constituem verdadeiros direitos de crédito do indivíduo, sendo, portanto, dever correlato do Estado prover sua concretização.

Sarlet (2001a) confirma que com a ascensão do Estado social, nascem os direitos de segunda dimensão, caracterizados por outorgarem aos indivíduos direitos a prestações sociais estatais, como saúde, educação, trabalho, assistência social, entre outras, demonstrando uma passagem das liberdades formais abstratas, conquistadas pelo liberalismo, para as liberdades materiais concretas.

Nas Constituições brasileiras, a partir da Carta de 1934 os direitos sociais passam a ser previstos, por influência da Constituição alemã de Weimar de 1919, contudo somente com a Constituição de 1988 os direitos sociais são contemplados com a marca da fundamentalidade. Essa última Constituição representa para Piovesan (2007) a reinvenção do marco jurídico brasileiro no campo da proteção dos direitos humanos, em especial dos direitos sociais.

Isso se confirma pela análise de índole topográfica e, por óbvio, finalística da Constituição vigente. A começar pelo seu artigo $6^{\circ}$ e pela apresentação da ordem social com uma amplo universo de normas que enunciam programas, tarefas, diretrizes e fins a serem perseguidos pelo Estado e pela sociedade. E como destacou Cunha Júnior (2008) a previsão dos direitos sociais em capítulo próprio do título dos direitos fundamentais cooperou para encerrar com o entendimento de que não gozavam de força vinculativa porque estavam previstos somente no capítulo da ordem econômica e social. 
Sem olvidar o arrojo da atual carta constitucional ao consagrar, em seu preâmbulo, a instituição de um Estado Democrático, destinado a assegurar o exercício dos direitos sociais e individuais, a liberdade, a segurança, o bem-estar, o desenvolvimento, a igualdade e a justiça como valores supremos de uma sociedade fraterna, pluralista e sem preconceitos.

Além da consagração do valor dignidade da pessoa humana como fundamento do Estado e, portanto, diretriz básica de todo ordenamento jurídico, principalmente dos direitos fundamentais sociais. Compreendida a dignidade da pessoa humana nos dizeres de Sarlet (2001b, p. 60) como:

[...] a qualidade intrínseca e distintiva de cada ser humano que o faz merecedor do mesmo respeito e consideração por parte do Estado e da comunidade, implicando, neste sentido, um complexo de direitos e deveres fundamentais que assegurem a pessoa tanto contra todo e qualquer ato de cunho degradante e desumano, como venham a lhe garantir as condições existenciais mínimas para uma vida saudável, além de propiciar e promover sua participação ativa co-responsável nos destinos da própria existência e da vida em comunhão dos demais seres humanos.

Compreendida, portanto, na relação de mútua dependência com os direitos fundamentais, conforma sinaliza Novelino (2009) quando diz que esses surgiram para atender a exigência da dignidade de proporcionar o pleno desenvolvimento da pessoa humana e somente pela existência deles é que a dignidade será respeitada.

Nos avanços do constituinte de 1988 nos direitos fundamentais, com reflexo nos sociais, são destaques, também, a ampliação do catálogo de direitos fundamentais com a previsão de um extenso rol, além da consagração da cláusula de abertura material ou de não tipicidade dos direitos fundamentais, prevista no parágrafo $2^{\circ}$, do artigo $5^{\circ}$, e, talvez, a mais audaciosa inovação, a previsão da aplicabilidade imediata de todas as normas definidoras de direitos e garantias fundamentais (artigo $5^{\circ}$, parágrafo $1^{\circ}$ ).

\subsection{A Eficácia Jurídica e Aplicabilidade das Normas Definidoras de Direitos Fundamentais}

O estudo da eficácia e aplicabilidade dos direitos fundamentais, sobretudo dos sociais, é decisivo para compreender a real possibilidade de concretização do direito à saúde na atual dogmática constitucional, foco central desse artigo. 
Torna-se necessário adiantar que não obstante previsão constitucional expressa sobre a eficácia das normas de direitos fundamentais, o assunto está longe de ser simples, pois existem consideráveis divergências teóricas e até mesmo ideológicas que não permitem dar um tratamento uniforme para a matéria, conforme será detalhado.

Mas, antes de adentrar especificamente nessa discussão da eficácia das normas definidoras de direitos fundamentais, convém realizar alguns apontamentos teóricos sobre eficácia jurídica em sede constitucional.

Ressalva-se, por ora, que não se trata da eficácia social, real obediência e aplicação da norma na sociedade, mas da eficácia que é condição para eficácia social, a jurídica, observando que, na atual realidade constitucional, o Direito não está alienado da eficácia social, pelo contrário, está atrelado a ela, na medida em que oferece mecanismos jurídico-operacionais eficientes para efetivação das normas constitucionais, principalmente de direitos fundamentais.

Concentrando-se na eficácia jurídica, é sabido que toda norma constitucional, seja formal ou material, possui essa eficácia, ou seja, tem capacidade para produzir efeitos, mas o grau dessa eficácia varia de acordo com o grau de normatividade. Nem todas as normas constitucionais possuem o mesmo alcance e significação normativa.

Para melhor esclarecer essa variação eficacial das normas constitucionais é imprescindível se valer da classificação trazida pelo professor José Afonso da Silva (1998). Esse autor, aliás, também observa que não há norma constitucional sem eficácia e aplicabilidade, mas existem aquelas que não produzem a plenitude dos efeitos jurídicos esperados, pois dependem de regulamentação jurídica ordinária ou complementar executória, prevista ou requerida.

Dessa forma, o autor divide as normas constitucionais em três tipos: normas constitucionais de eficácia plena, normas constitucionais de eficácia contida e normas constitucionais de eficácia limitada.

As normas constitucionais de eficácia plena são assim consideradas por possuírem normatividade suficiente para sua incidência imediata, não dependendo de qualquer imposição infraconstitucional.

Portanto, são normas de aplicabilidade direta, imediata e integral.

E, segundo Silva (1998), existe uma forte tendência em reconhecer eficácia plena e aplicabilidade imediata à maioria das normas constitucionais, mesmo em se tratando de normas de caráter socioideológico. Isso se coaduna com as bases apresentadas pelo Constitucionalismo contemporâneo de força normativa da Constituição e de efetivação dos direitos fundamentais, especialmente os sociais e econômicos.

As normas de eficácia contida pouco diferem da plena, pois possuem apli- 
cabilidade direta, imediata, mas não integral.

Assim, também não necessitam de integração legislativa, entretanto pode ocorrer a edição de uma lei com intenção de reduzir sua eficácia ou impor limites.

Silva (1998) entende que essas normas não são integrais, pois podem ter restrições previstas ou dependentes de regulamentação que limita sua eficácia e aplicabilidade. E, complementa, apresentando como características marcantes dessas normas a impossibilidade do legislador negar a própria norma constitucional; a existência de eficácia plena até o legislador expedir norma de contenção; a aplicabilidade direta e imediata; a possibilidade de existir um conceito ético, como bons costumes que, por si só, pode limitar a eficácia; e que sua eficácia pode ser rejeitada em razão de outras normas constitucionais, caso ocorra determinados fatos, como o estado de sítio.

O terceiro tipo de norma é a de eficácia limitada que se subdividem em normas constitucionais de princípio institutivo e normas constitucionais de princípio programático.

Em regra, as normas de eficácia limitada dependem de integração legislativa para produzirem seus efeitos, portanto são de aplicabilidade indireta, mediata e reduzida.

As normas de princípio institutivo são "aquelas através das quais o legislador constituinte traça esquemas gerais de estruturação e atribuições de órgãos, entidades ou institutos, para que o legislador ordinário os estruture em definitivo, mediante lei". (SILVA, 1998, p. 126).

Já as normas constitucionais de princípio programático são normas que o constituinte limitou-se a traçar-lhes os princípios ou programas para serem cumpridos pelos seus órgãos, visando atingir as finalidades sociais do Estado.

Silva (1998) sintetiza que essas normas estabelecem um dever para o legislador infraconstitucional, condicionam a edição de leis futuras, demonstram o modelo de Estado e de sociedade e influenciam a ordem jurídica, condicionam a atividade discricionária da administração, do legislador e do judiciário e criam situações jurídicas subjetivas, de vantagem ou desvantagem.

É necessário destacar que as normas programáticas, responsáveis por estabelecerem fins vinculativos ao Estado, normalmente contemplando direitos sociais, possuem eficácia jurídica. Afasta-se, portanto, do entendimento doutrinário que nega a esse tipo de norma qualquer eficácia e até mesmo não a considera como norma jurídica, mas sim meros conselhos e diretrizes futuras.

E, ainda, deve ser feita uma distinção entre normas programáticas atributivas de direitos sociais e econômicos das normas programáticas fixadoras de objeti- 
vos meramente políticos, sendo que essas últimas não conferem direitos imediatos. Já as normas programáticas atributivas de direitos sociais e econômicos, sobretudo os atrelados ao mínimo vital, devem ser aplicadas diretamente e vinculam imediatamente todos os poderes estatais.

Frisa-se que as normas constitucionais atributivas de direitos sociais são programáticas, mas desfrutam de aplicação direta e imediata.

Barroso (2000, p. 106) analisando as normas programáticas definidoras de direitos sociais assevera que:

É puramente ideológica, e não científica, a resistência que ainda hoje se opõe à efetivação, por via coercitiva, dos chamados direitos sociais. Também os direitos políticos e individuais enfrentaram, como se assinalou, a reação conservadora, até sua final consolidação.

Cunha Júnior (2008) diz que é inafastável a eficácia jurídica das normas constitucionais, observando que o único problema da eficácia das normas constitucionais, especialmente das programáticas, está na forma de jurisdição constitucional exercida em cada país. Prega, ainda, que uma jurisdição progressista, voltada a aproximar a norma da realidade, contribuirá para eficácia e efetividade das normas constitucionais. Arremata a idéia, destacando o papel do Judiciário que deve garantir a expansão dos direitos e sua afirmação em juízo, para gerar o progresso da democracia.

Canotilho (1997) ensina que o sentido das normas programáticas não é o atribuído pela doutrina tradicional como "simples programas", "exortações morais", "declarações", "sentenças políticas", sem gerar qualquer vínculo jurídico. E assevera que o valor jurídico constitucional das normas programáticas é igual a de outros preceitos da Constituição.

Para não restar dúvidas sobre a aplicabilidade direta e imediata das normas constitucionais definidoras de direitos sociais, convém acrescentar que o texto constitucional explicitou em seu artigo $5^{\circ}, \S 1^{\circ}$, o princípio da aplicabilidade imediata das normas definidoras de direitos fundamentais.

Dessa forma, fica reforçada a tese da eficácia e aplicabilidade imediata dos direitos sociais, pois são, reconhecidamente, direitos fundamentais.

Não obstante a menção direta e objetiva do artigo $5^{\circ}, \S 1^{\circ}$, auxiliando até mesmo a defesa da aplicabilidade dos direitos sociais, inúmeros debates foram travados pela doutrina em torno de sua significação e merecem ser retratados, até mesmo para solidificar a posição exposta.

É sabido que as normas definidoras de direitos fundamentais também 
apresentam variação de carga eficacial, como as normas constitucionais em geral, pois são direitos que desempenham diversas funções e suas formas de positivação são diferentes.

Obviamente, isso não desvaloriza esse princípio e não justifica a posição de que os direitos fundamentais somente são aplicados imediatamente se as normas que os definem são completas na sua hipótese e no seu dispositivo, conforme defende o professor Ferreira Filho (1998).

Dessa posição se infere, na verdade, a inutilidade do artigo $5^{\circ}, \S 1^{\circ}$, da Constituição, tendo em vista a afirmação de que esse princípio não tem o efeito de emprestar às normas carentes de concretização sua imediata aplicação.

É visível a incompatibilização dessa posição com o novo constitucionalismo, pois o escopo desse revolucionário artigo é evitar o esvaziamento dos direitos fundamentais, assegurando a plena produção de seus efeitos e sua concretização.

Contrapondo-se a essa posição temos a linha doutrinária em defesa da imediata e direta aplicação das normas de direitos fundamentais, ainda que de caráter programático, no sentido de que os direitos subjetivos nelas consagrados podem ser imediatamente realizados, sem necessidade de intermédio do legislador.

Tal linha doutrinária é difundida por Eros Roberto Grau, Luís Roberto Barroso, Dirley da Cunha Júnior, entre outros.

Segundo Grau (1997), a norma em comento obriga os Poderes Públicos, especialmente o Judiciário, a dar exequibilidade imediata das normas definidoras de direitos e garantias, independentemente da produção de qualquer ato legislativo ou administrativo. O Poder Judiciário está autorizado a suprir a ausência de norma legislativa ou medida administrativa que impeçam a exequibilidade imediata de um direito fundamental. Complementa, ainda, o autor que essa norma autoriza o Judiciário a "inovar o ordenamento jurídico", a "produzir direito".

Barroso (2000) destaca a importância da inserção deste princípio no texto constitucional e afirma que a competência para aplicar as normas constitucionais é do Poder Judiciário quando descumpridas por seus destinatários. Complementa, ainda, dizendo que a não existência de norma integradora não pode frustrar a aplicação de preceito constitucional pelo magistrado, de acordo com a Lei de Introdução ao Código Civil.

Nesse sentido, Cunha Júnior (2008), em aprofundada pesquisa, acrescenta que em votação plenária na Assembléia Nacional Constituinte o Deputado Presidente Ulysses Guimarães explicou o sentido dado ao artigo $5^{\circ}, \S 1^{\circ}$, afastando a necessidade de lei complementar para aplicabilidade dos direitos e garantias fundamentais. 
E complementa, a seguir, Cunha Júnior (2008, p. 276):

Ademais disso, também considerando o método histórico de interpretação do art. $5^{\circ}, \S 1^{\circ}$, da $\mathrm{CF}$, e consciente de que deve o jurista perquirir no sistema normativo, até a exaustão, todas as potencialidades dos comandos normativo-constitucionais, notadamente o ora sob investigação, firmamos nossa posição em favor da direta e imediata aplicação de todas as normas definidoras de direitos fundamentais, independentemente de qualquer interpositio legislatoris, que é até desnecessária. Isso significa que a normaprincípio do art. $5^{\circ}, \S 1^{\circ}$, da Constituição Federal, tem por finalidade irrecusável propiciar a aplicação imediata de todos os direitos fundamentais, sem necessidade de qualquer intermediação concretizadora, assegurando, em última instância, a plena justiciabilidade destes direitos, no sentido de sua imediata exigibilidade em juízo, quando omitida qualquer providência voltada à sua efetivação.

Essa doutrina prega força máxima ao artigo $5^{\circ}, \S 1^{\circ}$, da Constituição. Os dispositivos de direitos fundamentais são dotados de autossuficiência normativa, suplantando toda omissão ou deficiência infraconstitucional.

É preciso enfatizar que tal comando confere aos poderes públicos a atribuição de tornar os direitos fundamentais reais e efetivos.

Assim, diante da omissão dos órgãos de direção política e em caso de lacuna legislativa, cumpre a qualquer órgão do Poder Judiciário, quando provocado, conferir ao titular o desfrute imediato de um direito fundamental, pleiteado no caso concreto, cumprindo, dessa maneira, sua obrigação de realizar concretamente os comandos normativos constitucionais, como é o caso do artigo em análise.

Convém repisar que mesmo as normas programáticas atributivas de direitos fundamentais sociais, ou seja, aquelas que fixam programas, tarefas e finalidades a serem cumpridas pelos órgãos de direção política e, portanto, necessitam de lei, possuem plena aplicabilidade, requisitando somente uma atuação maior do Poder Judiciário no tocante a complementação e concretização dos direitos fundamentais. A ausência de legislação não impede que qualquer órgão do Poder Judiciário aplique imediatamente as normas definidoras de direitos fundamentais, fazendo com que as pessoas possam desfrutar das posições jurídicas subjetivas ali consagradas.

Diante da Constituição brasileira de 1988, compromissada com os anseios do Estado social democrático, outra não deve ser a interpretação dessa norma-princípio. Aliás, a desigualdade social que permeia o Brasil faz emergir no Constitucionalismo contemporâneo a urgente necessidade de evoluir nas formas 
de proteção dos direitos fundamentais, sobretudo, sociais e de adotar uma nova dogmática jurídico-constitucional.

\section{O DIREITO À SAÚDE À LUZ DA TEORIA DOS DIREITOS FUNDAMENTAIS}

O direito à saúde é integrante dos denominados direitos sociais, sendo, inegavelmente, um direito fundamental. Trata-se, portanto, de um direito social fundamental. Contudo, não se pode negar que o direito à saúde dentro da teoria dos direitos fundamentais se encontra em uma categoria que enfrenta algumas dificuldades relacionadas à sua plena efetivação.

Para melhor compreensão das razões dessas dificuldades, convém realizar a exposição de uma classificação que leva em conta as múltiplas funções que os direitos fundamentais exercem na ordem jurídica.

Para isso, deve-se, inicialmente, referenciar a teoria clássica desenvolvida por Jellinek (1981), denominada teoria dos quatro status, base teórica da proposta classificatória que revelará o enquadramento do direito à saúde na moderna teoria dos direitos fundamentais.

Cunha Júnior (2008), ao investigar essa teoria, a qualifica como sendo de grande contribuição para a teoria geral dos direitos fundamentais, pois analisa como o indivíduo, enquanto membro de uma comunidade, se vincula ao Estado. Acrescentando, ainda, que o indivíduo qualifica-se sob diversos aspectos, e que as possíveis relações nas quais pode encontrar-se com o Estado colocam-no numa série de condições juridicamente relevantes, daí resultando os quatro status: status passivo, status libertatis, status positivo e status activus.

Pelo status passivo, o indivíduo está subordinado ao Estado, sujeitando-se a um conjunto de deveres e não de direitos. O Estado impõe ordens e proibições. Pelo status libertatis, o indivíduo detém uma esfera individual de liberdade que não sofre intervenção estatal. Trata-se das liberdades. Pelo status positivo, ao indivíduo são franqueadas as instituições estatais para exigir do próprio Estado determinadas prestações positivas que possibilitem a satisfação de certas necessidades. Tem-se uma situação positiva, da qual derivam autênticos direitos públicos subjetivos. E pelo status activus, o indivíduo tem a possibilidade de participar ativamente da vontade política do Estado.

A partir dessas posições fixadas por Jellinek (1981), surge a referida proposta classificatória, condizente aos novos contornos constitucionais, e defendida, 
entre nós, por Sarlet (2001a), baseada em Alexy (2008), que divide os direitos fundamentais em dois grandes grupos: a) os direitos fundamentais como direito de defesa e b) os direitos fundamentais como direitos a prestações (de natureza fática e jurídica), que, por sua vez, se subdividem em (b1) direitos a prestações em sentido amplo (compreendendo os direitos à proteção e os direitos à participação na organização e procedimento) e (b2) direitos a prestações em sentido estrito (direitos a prestações materiais sociais ou simplesmente direitos sociais).

Os direitos fundamentais como direitos de defesa, segundo Cunha Júnior (2008) são todos aqueles que desempenham a função de tutela da autonomia individual, repelindo de seu âmbito a ação abusiva do Estado. São o status libertatis que correspondem aos direitos de primeira geração, compreendendo, entre eles, as liberdades fundamentais, a igualdade perante a lei, o direito à vida e o direito a propriedade.

Esses são os direitos que consagram ao sujeito o poder de exercer positivamente seus próprios direitos e de exigir omissões do Estado e de particulares, evitando qualquer tipo de lesão.

Concluindo, então, a doutrina dos direitos fundamentais que não existem grandes dificuldades quanto à sua direta e imediata aplicabilidade.

Passemos, então, para análise dos direitos fundamentais como direitos a prestações, categoria na qual se situa o direito à saúde.

Cunha Júnior (2008, p. 260) explica essa categoria de direitos fundamentais como sendo aquelas:

posições jurídicas que habilitam o indivíduo a exigir do Estado uma postura ativa, no sentido de que este coloque à disposição daquele, prestações de natureza normativa ou material, que possam implementar as condições fáticas, e pressupostos que permitam o efetivo exercício das liberdades fundamentais. São o status positivus de Jellinek e correspondem aos direitos de segunda dimensão, fruto da transformação do Estado Liberal de Direito para o Estado Democrático Social de Direito. Vale dizer, a consagração desses direitos marca a superação de uma perspectiva liberal, em que se passa a considerar o homem para além de sua condição individual. Com eles surgem para o Estado certos deveres de prestações positivas.

Portanto, exige-se, aqui, um agir do Estado, objetivando a redução das desigualdades e o atendimento das necessidades mais vitais.

Essa atuação estatal, exigida por esses direitos fundamentais, pode referirse, ainda, a uma prestação jurídica ou uma prestação material, conforme o objeto da 
pretensão seja uma atuação normativa do Estado ou uma utilidade concreta a ser proporcionada por ele. Melhor dizendo, existem direitos fundamentais que dependem de simples atuação normativa do Estado para terem sentido e apresentarem conteúdo jurídico pleno para o exercício do indivíduo (prestação jurídica) e outros direitos fundamentais que dependem de um benefício material, consistente em um bem ou serviço, a ser prestado pelo Estado (prestação material).

É nesse último tipo de direitos fundamentais que se enquadram os direitos sociais, e, por conseguinte, o direito à saúde. Está inserido nos denominados direitos a prestações em sentido estrito, que são os direitos a prestações materiais sociais.

Na verdade, nessa última categoria, a função de prestação dos direitos fundamentais tem a missão de prover o indivíduo de condições para exigir do Estado a imediata realização de políticas públicas socialmente ativas, criando, por conseqüência, as condições materiais e institucionais para o exercício desses direitos, e nisso consiste a atuação exigida do Estado à prestação material. (CUNHA JÚNIOR, 2008). E, mais, haverá um direito à prestação material quando se está diante de um direito relacionado ao mínimo vital, como é o caso do direito à saúde.

$\mathrm{O}$ direito à saúde corresponde aos típicos direitos sociais, pressupondo não exatamente uma regulamentação normativa, embora exista, mas uma atuação positiva material do Estado, com a finalidade de propiciar serviços, instituições e bens.

Diante disso, boa parte da doutrina nega a condição do direito à saúde como verdadeiro direito, o que, obviamente, não deve ser aceito.

E, nesse sentido, propaga-se o entendimento a respeito das maiores dificuldades para aplicabilidade direta e imediata do direito à saúde, por se tratar de um direito fundamental social prestacional. Invoca-se contra essa aplicabilidade, principalmente, a necessidade de condições econômicas favoráveis, tendo em vista o alto custo desse direito para o Estado.

Todavia, cabe antecipar, que havendo disponibilidade de recursos econômicos, ainda que em decorrência de remanejamento, é defensável a plena aplicabilidade desse direito.

Barroso (2000) aponta as "verdadeiras" razões que diferencia a aplicabilidade imediata dos direitos fundamentais de defesa dos direitos fundamentais a prestação, sendo uma, de natureza ideológica, uma vez que os direitos de defesa sempre foram a bandeira do pensamento político burguês que representa, modernamente, a classe dominante, de modo que eles traduzem a proteção jurídica dos interesses dessa classe e sua concretização, por isso mesmo, não encontra empeço de natureza política, e a outra, de natureza operacional, na medida em que esses direitos têm por 
conteúdo, essencialmente, uma abstenção por parte do Estado ou do particular, e sua realização, por conseguinte, não depende de qualquer prestação dos órgãos estatais, para além de ter em seu benefício a própria lei da inércia.

\subsection{A Aplicabilidade Imediata do Direito Fundamental à Saúde}

Diante do enquadramento do direito à saúde como direito fundamental social, torna-se inegável sua aplicabilidade imediata.

O direito à saúde detém aplicabilidade direta e imediata, como todas as normas constitucionais definidoras de direitos fundamentais, advertindo que sua aplicabilidade independe de sua densidade normativa, ou seja, o gozo desse direito fundamental não fica subordinado ao legislador ordinário.

Assenta-se, ainda, que o direito à saúde, em uma perspectiva subjetiva, é direito público subjetivo, investindo seus titulares em posições jurídicas imediatamente desfrutáveis, a serem materializadas geralmente por prestações positivas.

Oliveira (2004) no mesmo sentido, configura a saúde como um direito público subjetivo, capaz de ser exigido diante de falha do Poder Público, que não pode agir sem responsabilidade no atendimento desse dever assistencial.

Assim, o Estado brasileiro para assegurar o direito à saúde precisa atuar de forma permanente em benefício do indivíduo, sendo obrigado a garantir-lhe o mínimo existencial, ou seja, a fornecer-lhe recursos materiais indispensáveis para uma existência digna, como providência reflexa típica do modelo de Estado do Bem-Estar Social.

Por óbvio, as prestações-objeto do direito à saúde, como de outros direitos fundamentais sociais, dependem da disponibilidade econômica do Estado ou de meios jurídicos necessários a satisfazê-lo.

Mas, conforme ressalta Cunha Júnior (2008), essas características limitadoras dos direitos sociais, inclusive do direito à saúde, não negam, e jamais podem negar, a sua devida justiciabilidade. Não pode, em razão delas, ser recusada a estes direitos a condição de verdadeiros direitos subjetivos e não pode, também, ser obstada ou embaraçada sua plena e imediata aplicabilidade.

Complementa Cunha Júnior (2008, p. 294):

Ora, na hodierna dogmática constitucional, com o reconhecimento de um direito fundamental à efetivação da Constituição, assiste-se, sem dúvida, a um deslocamento da doutrina dos direitos fundamentais dentro da reserva da lei para a doutrina da reserva da lei dentro dos direitos fundamentais, de tal modo que é incogitável negar o caráter jurídico e, conseqüentemente, 
a exigibilidade e acionabilidade dos direitos fundamentais sociais, que são autênticos direitos subjetivos. Todos os direitos sociais geram imediatamente posições jurídicas favoráveis ao indivíduo, exigíveis, desde logo, inobstante possam apresentar teores eficaciais distintos. Esses direitos, portanto, “são verdadeiros 'direitos subjetivos', na acepção mais comum da palavra”, máxime quando necessários à garantia do padrão mínimo social.

Ademais, a Constituição não reconhece direitos fundamentais sem conteúdo, sempre existindo um conteúdo mínimo e essencial, a possibilitar a imediata e plena fruição dos direitos conferidos.

Nesse sentido, o dever do Estado na garantia do direito à saúde reside no nível mínimo essencial de saúde. O Estado deve sempre proteger e garantir aos seus indivíduos um nível mínimo de saúde, mesmo porque se trata de um direito relacionado à vida e a dignidade da pessoa humana.

Portanto, o dever do Estado consiste na existência de hospitais públicos ou postos públicos de saúde, da disponibilidade de vagas e leitos nos hospitais e postos já existentes, do fornecimento gratuito de remédios e existência de profissionais suficientes ao desenvolvimento e manutenção das ações e serviços públicos de saúde. $\mathrm{Na}$ ausência ou insuficiência dessas prestações materiais, cabe indiscutivelmente a efetivação judicial desse direito. Assim, assiste ao titular do direito de exigir judicialmente do Estado uma dessas providências fáticas necessárias ao desfrute da prestação que lhe constitui o objeto. (CUNHA JÚNIOR, 2008, p. 314).

Aliás, a reserva do possível, significante formulado por Canotilho (1997) para designar que os direitos sociais depende de disponibilidade dos recursos econômicos, amparado na doutrina germânica e na jurisprudência do Bundesverfassungsgericht (Vorberhalt des Möglichen), deve ser compreendida no Brasil como condicionamento aos direitos sociais, mas desde que não desrespeite o mínimo de prestações estatais capazes de garantir a sobrevivência humana, pois o direito a um mínimo vital deve ser garantido imediatamente pelo Poder Público, sob pena de incorrer em omissão, devendo, posteriormente, ganhar relevo a discussão das limitações orçamentárias.

Mesmo porque transladar uma teoria desenvolvida na Alemanha para aplicar no Brasil implica necessariamente uma adequação a partir da história e das condições socioeconômicas dos países, considerando seu contextos jurídicos e sociais totalmente distintos. Krell (2002, p. 108-109), autor alemão, residente no Brasil desde 1993, observa: 
Devemos nos lembrar também que os integrantes do sistema jurídico alemão não desenvolveram seus posicionamentos para com os direitos sociais num Estado de permanente crise social e milhões de cidadãos socialmente excluídos. Na Alemanha - como nos outros países centrais - não há uma grande contingente de pessoas que não acham uma vaga nos hospitais mal equipados da rede pública; não há a necessidade de organizar a produção e distribuição da alimentação básica a milhões de indivíduos para evitar sua subnutrição ou morte; não há altos números de crianças e jovens fora da escola; não há pessoas que não conseguem sobreviver fisicamente com o montante pecuniário de assistência social que recebem, etc. Temos certeza de que quase todos os doutrinadores do Direito Constitucional alemão, se fossem inseridos na mesma situação sócio-econômica de exclusão social com a falta de condições mínimas de uma existência digna para uma boa parte do povo, passariam a exigir com veemência a interferência do Poder Judiciário, visto que este é obrigado a agir onde os outros Poderes não cumprem as exigências básicas da constituição (direito à vida, dignidade humana, Estado Social).

A próposito, não se deve olvidar que é indissociável ao direito à saúde o direito à vida, portanto, a alegação de ausência de recursos públicos, apesar de considerável, não deve prevalecer.

Ora, a partir do momento que as Cortes brasileiras proclamam essa associação, irrelevantes se tornam as questões de alocação de recursos públicos, visto que o direito à saúde adquire força quase absoluta, tornando os demais fatores envolvidos meros interesses secundários do Estado.

Portanto, a alegação da reserva do possível não deve justificar a omissão estatal, pois de outro modo, inviabilizaria a efetivação do direito à saúde, eximindo o Estado de responsabilidade.

\section{CONCLUSÃO}

O Constitucionalismo contemporâneo traz uma evolução de paradigma, surpreendendo pela formação do Estado constitucional de direito, pelo reconhecimento da força normativa da Constituição, da expansão jurisdicional, do desenvolvimento de uma nova dogmática da interpretação constitucional e, principalmente, pela centralidade dos direitos fundamentais, o que tem propiciado o fortalecimento da defesa da efetividade dos direitos fundamentais sociais, em especial o direito à saúde.

A partir da compreensão de que a consagração dos direitos fundamentais é 
resultado de um processo de construção histórica, se identifica que, na atual quadra, a sociedade conclama por um Estado mais participativo, positivamente intervencionista, sobretudo nos setores sociais e econômicos. É exigido do Estado, fundamentalmente, uma atuação efetiva na garantia dos direitos fundamentais de segunda dimensão, dos direitos sociais.

A Constituição Federal de 1988, com fundamento na dignidade da pessoa humana, representa um impulso na efetivação dos direitos fundamentais sociais por meio de inúmeros dispositivos, destacando-se, entre eles, o da aplicabilidade imediata das normas definidoras de direitos fundamentais.

Apesar da previsão constitucional expressa, o estudo da eficácia e aplicabilidade dos direitos fundamentais não se revela uma tarefa simples. Algumas teorias foram propostas, mas o presente artigo firma sua defesa pela que consagra a aplicabilidade imediata de todas as normas de direitos fundamentais, inclusive as definidoras de direitos sociais, de caráter programático.

Assim, sendo o direito à saúde um direito fundamental social prestacional é latente sua imediata aplicabilidade e seu caráter de direito público subjetivo, sobretudo pela sua correlação com o mínimo vital.

Há que se considerar que é inegável que a efetivação do direito à saúde exige disponibilidade orçamentária e está vinculada a limitação dos recursos financeiros, entretanto essa restrição não pode autorizar a omissão do Estado na garantia do mínimo essencial à sobrevivência.

\section{REFERÊNCIAS}

ALEXY, Robert. Teoria dos direitos fundamentais. Trad. Virgílio Afonso da Silva: São Paulo: Malheiros, 2008.

BARROSO, Luís Roberto. O direito constitucional e a efetividade de suas normas: limites e possibilidades da Constituição brasileira. 4. ed. Rio de Janeiro: Renovar, 2000.

. "Neoconstitucionalismo e constitucionalização do direito. O triunfo tardio do direito constitucional no Brasil". Jus Navigandi, Teresina, ano 10, n.851, 1 nov. 2005. Disponível em http://jus.uol.com.br/revista/texto/7547. Acesso em: 20 de jan. de 2015. 
BIGOLIN, Giovani. “A reserva do possível como limite à eficácia e efetividade dos direitos sociais". Revista de Doutrina da $4^{a}$ Região, Porto Alegre, n. 01, jun. 2004. Disponível em $<$ http://www.revistadoutrinatrf4.gov.br/artigos/constitucional/giovani_bigolin. htm $>$ Acesso em 10 de nov. 2014.

BONAVIDES, Paulo. Curso de direito constitucional. 9. ed. São Paulo: Malheiros, 2001.

. Constituinte e Constituição, a democracia, o federalismo e a crise contemporânea. Fortaleza: Edições Universidade Federal do Ceará/PROED, 1985.

. História constitucional do Brasil. 3 ed. São Paulo: Editora Paz e Terra, 1991.

BOURDIEU, Pierre. A dominação masculina. Rio de Janeiro: Bertrand Brasil, 1999.

CANOTILHO, J. J. Gomes. Direito constitucional e teoria da constituição. 3. ed. Coimbra: Almedina, 1997.

. Constituição dirigente e vinculação do legislador: contributo para a compreensão das normas constitucionais programáticas. Coimbra: Coimbra Ed., 1994.

COMPARATO, Fábio Konder. A afirmação histórica dos direitos humanos. 2. ed. São Paulo: Saraiva, 2001.

. "A democratização dos meios de comunicação de massa". In: Revista USP, São Paulo, n. 48, p. 6-17, dezembro/fevereiro 2000-2001.

CUNHA JÚNIOR, Dirley da. Controle judicial das omissões do poder público: em busca de uma dogmática constitucional transformadora à luz do direito fundamental à efetivação da constituição. 2. ed. São Paulo: Saraiva, 2008.

DALLARI, Sueli Gandolfi. Os Estados brasileiros e o direito à saúde. São Paulo: Hucitec, 1995.

DINIZ, Maria Helena. Norma constitucional e seus efeitos. 5. ed. São Paulo: Saraiva, 2001.

DUARTE, Francisco Carlos. "Qualidade de vida: a função social do Estado”. In: Revista da Procuradoria Geral do Estado de São Paulo, São Paulo, n. 41, junho/1994.

FERRAJOLI, Luigi. “Passado y Futuro Del Estado de Derecho”. In: Miguel Carbonell (Org.). Neoconstitucionalismo(s). Madrid: Editorial Trotta, p. 13-29, 2003. 
FERRARI, Regina Maria Macedo Nery. Normas constitucionais programáticas: normatividade, operatividade e efetividade. São Paulo: Revista dos Tribunais, 2001.

FERREIRA FILHO, Manoel Gonçalves. Direitos humanos fundamentais. 2. ed. São Paulo: Saraiva, 1998.

GOMES JÚNIOR, Luiz Manoel. "Saúde - tratamento médico - limites para exigência de custeio pelo Poder Público - abuso de direito - inadmissibilidade". In: Revista dos Tribunais, São Paulo, Ano 95, v. 844, Fev./ 2006.

GRAU, Eros Roberto. A ordem econômica na Constituição de 1988. 3. ed. São Paulo: Malheiros, 1997.

JELLINEK, Georg. Teoría general del Estado. Trad. Fernando de los Ríos. Buenos Aires: Albatroz, 1981.

KRELL, Andreas Joachim. Direitos sociais e controle judicial no Brasil e na Alemanha: os (des) caminhos de um direito constitucional “comparado”. Porto Alegre: Sérgio A. Fabris, Editor, 2002.

LENZA, Pedro. Direito constitucional esquematizado. 13 ed. São Paulo: Saraiva, 2009.

LOEWENSTEIN, Karl. Teoría de la Constitución. 2. ed. Trad. Alfredo Gallego Anabitarte. Barcelona: Ed. Ariel, 1970.

MIRANDA, Jorge. Manual de direito constitucional, t. IV. 3. ed. Coimbra: Coimbra Ed., 1996.

MORAES, Alexandre de. Direito constitucional. 12. ed. São Paulo: Atlas, 2002.

MOREIRA, Eduardo Ribeiro. Neoconstitucionalismo: a invasão da Constituição. São Paulo: Método, 2008.

NOVELINO, Marcelo. Direito constitucional. 3. ed. São Paulo: Método, 2009.

OLIVEIRA, Euclides Benedito de. "Responsabilidade do Estado pelo atendimento integral à saúde da pessoa humana". In: Revista do Instituto de Pesquisas e Estudos, n. 39, Faculdade de Direito de Bauru, jan./abr. 2004.

PIOVESAN, Flávia. Direito constitucional - Temas atuais. Homenagem à Professora Leda Pereira da Mota/ coordenador Roberto B. Dias da Silva. São Paulo: Método, 2007. 
ROCHA, Cármen Lúcia Antunes. "O constitucionalismo contemporâneo e a instrumentalização para a eficácia dos direitos fundamentais". In: Revista Trimestral de Direito Público, n. 16, p. 39-58, 1996.

SARLET, Ingo Wolfgang. A eficácia dos direitos fundamentais. 2. ed. Porto Alegre: Livraria do Advogado, 2001a.

. Dignidade da pessoa humana e direitos fundamentais na Constituição Federal de 1988. Porto Alegre: Livraria do advogado, 2001b.

SCHWARTZ, Germano André Doederlein. Direito à saúde: efetivação em uma perspectiva sistêmica. Porto Alegre: Livraria do Advogado, 2001.

SILVA, José Afonso da. Aplicabilidade das normas constitucionais. 3. ed. São Paulo: Malheiros, 1998.

. Curso de direito constitucional positivo. 22 ed. São Paulo: Malheiros, 2003.

TAVARES, André Ramos. Curso de direito constitucional. São Paulo: Saraiva, 2002. 